\title{
Kinetic study, optimization and comparison of sun drying and superheated steam drying of asam gelugor (Garcinia cambogia)
}

\author{
Lim, G.W., Jafarzadeh, S. and *Norazatul Hanim, M.R. \\ Food Technology Division, School of Industrial Technology, Universiti Sains Malaysia, 11800 USM, \\ Penang, Malaysia
}

\begin{abstract}
Article history:
Received: 12 August 2019 Received in revised form: 17 September 2019

Accepted: 20 September 2019 Available Online: 17 October 2019
\end{abstract}

\section{Keywords:}

Garcinia cambogia,

Kinetic study,

Superheated steam drying,

Sun drying,

Optimization

DOI:

https://doi.org/10.26656/fr.2017.4(2).288

\begin{abstract}
The purposes of present study are to compare the kinetic drying of the G. cambogia through sun drying and superheated steam drying (SSD) method and optimizing the quality of SSD of it through response surface methodology. G. cambogia fruit rinds were dried at temperature of $150^{\circ} \mathrm{C}, 200^{\circ} \mathrm{C}$ and $250^{\circ} \mathrm{C}$. The drying curves were fitted into the mathematical model of Page, Lewis and Henderson-Pabis models. Page model was found to be the best in describing the drying behavior of G. cambogia. Drying rate constant $(k)$ increased as temperature increased and SSD method had overall higher drying rates ranged from $5.929 \times 10^{-5}$ to $5.861 \times 10^{-4} \mathrm{~min}^{-1}$ than sun drying method which was $4.980 \mathrm{x}$ $10^{-6} \mathrm{~min}^{-1}$. Total acid number showed a trend of increased followed by decreased over drying time. superheated steam drying process of G. cambogia fruit rinds was optimized by using response surface methodology employing a central composite design. Drying time and temperature were the factors in optimization while moisture content (wet basis), acid number and lightness $\left({ }^{*} \mathrm{~L}\right)$ were the response parameters. Experimental results were fitted to a second-order polynomial model and the model fitness and optimal drying condition were determined by regression analysis and analysis of variance. The optimal conditions for superheated steam drying of G. cambogia fruit rinds were identified as $46.60 \mathrm{mins}$ and $150^{\circ} \mathrm{C}$ with the composite desirability of 0.913 . Application of superheated steam drying under controlled conditions resulted in faster drying process and better quality of dried G. cambogia than conventional sun drying technique.
\end{abstract}

\section{Introduction}

Garcinia is the largest genus of Guttiferae (syn. Clusiaceae) family. It is a native species distributed in India, Nepal and Sri Lanka and has been brought to China, Malaysia and Philippines (Jayaprakasha, 2002). It produces small, green fruit about 1.5 inches in diameter that resemble pumpkins and changes from green to yellow colour during the ripening process. The fruits are edible however too acidic. Various parts of the fruit are used as food preservatives, spices, and food bulking agents. It is most often used for culinary especially fish curries and 'Asam laksa' because of the sour taste and medicinal purposes (Osman and Milan, 2006). The fruit extract of G. cambogia has been used for constipation, hemorrhoids, and intestinal parasites. Other medicinal uses include edema, rheumatism, and irregular menstruation. Although numerous chemicals have been isolated from $G$. cambogia fruit, hydroxycitric acid (HCA) is considered the active ingredient for weight loss (Haber et al., 2018). Several clinical studies on the efficacy of G. cambogia for obesity have been conducted (Upadhyay et al., 2013; Gogoi et al., 2014). Due to its excellent therapeutic value, G. cambogia are being planted and produced in mass quantities and is an important economic product in India.

Thermal processing is one of the most important methods of food preservation primarily intended to inactivate enzymes, deteriorative microorganisms and reduce water activity by dehydration. For decades, conventional sun drying (SD) method was applied to enhance the shelf life of the fruits due to low drying cost. The traditional method of drying is by slicing $G$. cambogia into thin slices and dehydrated under the sun. However, the quality of the dried fruits is difficult to control as drying proceeds in an open environment (Rittirut and Siripatana, 2006)

Superheated steam is generated when steam is further heated to raise the temperature above saturation temperature. The properties of superheated steam and the benefits it brings gain more acceptance and has been 
used to dehydrate a variety of products. According to Mujumdar (2006), superheated steam drying (SSD) can better preserve dried food quality due to lack of air. Recent application of superheated steam in food products are banana slices (Hamawand et al., 2014), potato chips (Caixeta et al., 2002), shrimps (Prachayawarakorn et al., 2002), instant Asian noodles (Pronyk et al., 2004), vegetables, herbs and spices (Van Deventer and Heijmans, 2001).

To the best of our knowledge, no research has been carried out on the drying of $G$. cambogia by superheated steam drying (SSD) method and compared it with sun drying (SD). Hence, current study was conducted to improve the dried quality of G. cambogia by application of superheated steam in the drying process under controlled conditions. The kinetic drying of superheated steam drying method and sun drying method were determined and optimization of the superheated steam dried quality of G. cambogia was done by using response surface methodology (RSM).

\section{Materials and methods}

\subsection{Materials}

\subsubsection{Garcinia cambogia fruit}

Ripen G. cambogia fruits are freshly harvested on a weekly basis from an orchard located in Selama, Perak, Malaysia. The fresh fruits are wrapped with papers, kept in plastic bags and transported to the laboratory. The fruits are stored in chiller (Panasonic, NR-BL307N, Indonesia) at $10 \pm 1^{\circ} \mathrm{C}$ to maintain its freshness for further use. Each G. cambogia fruit weighs 300 to $350 \mathrm{~g}$ and depending on the fruits' sizes, two to three fruits are needed for each superheated steam drying in order to obtain kinetic drying curve.

\subsubsection{Chemicals and reagents}

Ethanol (approximately 96\%), 2-propanol and toluene were purchased from QRëCTM, New Zealand. Potassium hydroxide was obtained from Systerm ${ }^{\circledR}$, Shah Alam, Malaysia. Phenolphthalein was purchased from Sigma-Aldrich, St. Louis, Missouri, United States. All the chemicals and reagents purchased were analytical grade.

\subsection{Sample preparation}

G. cambogia fruits were washed thoroughly to remove dirt and gums on the surface. The fruits were then patted dry with a paper towel and sliced into thin slices approximately $2.0 \pm 0.5 \mathrm{~mm}$ without removing the skin to prevent moisture evaporate and diffuse off from the thin slice in radial dimension. Sliced fruits were kept in the resealable bag prior to drying.
2.3 Drying kinetics of superheated steam drying and sun drying of G. cambogia

\subsubsection{Superheated steam drying}

Sliced G. cambogia fruits were spread in a single layer on drying trays. Superheated steam oven (SHARP Healsio, AX-1500 (K), Osaka, Japan) was turned on to the superheated steam mode and was preheated to the desired temperature. Superheated steam drying of $G$. cambogia was done at 150,200 and $250^{\circ} \mathrm{C}$. During the drying process, samples were taken at different time intervals and instantaneously cooled to room temperature in dessicator. Samplings were done at 0, 10, 20, 30, 40, 50, 60, 75 and 90 mins. Collected samples were blended using a blender (PENSONIC, PB-3205, Malaysia) and packed in resealable polyethylene plastic bags and stored for further experiments.

\subsubsection{Sun drying}

A single layer sliced G. cambogia fruits were distributed on a drying mesh and dried under the sun. The fruit slices were left exposed to the sun in an open environment to imitate the commercial sun drying method. However due to time constraints, sun drying of samples was done for $6 \mathrm{hrs}$ only. Samplings were done at time intervals: $0.0,0.5,1.0,1.5,2.0,2.5,3.0,4.0,5.0$ and 6.0 hrs. The collected samples were blend, packed and stored for further analysis similar to superheated steam drying samples.

\subsection{Thin layer model}

Page model, Lewis model, and Henderson-Pabis model were used to describe the drying behavior of $G$. cambogia fruit rinds. These three semi-theoretical models have been widely used to quantify drying kinetics of various foodstuffs such as mushrooms (Giri and Prasad, 2007), basil leaves (Kadam et al., 2011) and lactose powder (McMinn, 2006). The models were derived from Fick's law by simplification and are less time consuming than theoretical models in calculations (Guillard et al., 2013). Equation 1 shows the equation suggested by Lewis model.

Page (Page, 1949) then proposed a model to overcome the shortcoming of Lewis model by introducing an empirical parameter, $y$ resulting in Equation (2):

$$
\begin{aligned}
M R & =\frac{M-M_{e}}{M_{i}-M_{e}}=\exp (-k t) \\
M R & =\frac{M-M_{e}}{M_{i}-M_{e}}=\exp \left(-k t^{n}\right)
\end{aligned}
$$

Henderson and Pabis (Henderson, 1974) did some modification on Lewis equation, by adding a constant $a$ 
in the exponential term (Equation (3)).

$$
M R=\frac{M-M_{e}}{M_{i}-M_{e}}=a \exp (-k t)
$$

Where $M R$ is the moisture ratio; $M$ is the moisture content at any time t; $M_{e}$ is the equilibrium moisture content; $M_{i}$ is the initial moisture content; $k$ is the drying constant $\left(\min ^{-1}\right) ; n$ and $a$ are model constants (dimensionless)

The equation proposed in Page model, Lewis model and Henderson-Pabis model (Equations 1-3) were linearized and the empirical constants, $a$ and $n$ and drying rate constant, $k$ were determined and evaluated according to coefficient of determination, $\mathrm{R}^{2}$ (Roberts et al., 2008). The linearized Lewis equation is in the form of

$$
\ln (M R)=-k t+1
$$

where the drying constant, $k$ is the gradient of $\ln (M R)$ versus $t$ curve. The form of linearized Page equation is

$$
\ln [-\ln (M R)]=\ln (k)+n \ln (t)
$$

where the drying constants, $k$ and dimensionless constant, $n$ were determined from the intercept and slope of the $\ln [-\ln (M R)]$ versus $\ln (\mathrm{t})$ curve respectively. The linearized Henderson-Pabis equation is in the form of

$$
\ln (M R)=-k t+a
$$

where the drying constants, $k$ and dimensionless constant, $a$ were determined from the intercept and slope of the $\ln (M R)$ versus time curve.

The calculated constants were evaluated according to $\mathrm{R}^{2}$ (coefficient of determination) value which higher $\mathrm{R}^{2}$ indicated the model is fitted to the kinetic drying curve of G. cambogia. RMSE (root mean square error) and $\mathrm{X}^{2}$ (chi-square) values were also calculated to better support $\mathrm{R}^{2}$ value before drawing conclusion on the model which best fitted the drying curve (Onwude et al., 2016). The RMSE and $\mathrm{X}^{2}$ is calculated using Equation (7) and (8), respectively.

$$
\begin{gathered}
R M S E=\sqrt{\frac{1}{N} \sum_{i=1}^{N}\left(M R_{\text {exp }, i}-M R_{\text {pred }, i}\right)^{2}} \\
\chi^{2}=\frac{\sum_{i=1}^{N}\left(M R_{\text {exp }, i}-M R_{\text {pred }, i}\right)^{2}}{N-n_{p}}
\end{gathered}
$$

Where; $M R_{\text {exp }, i}$ is the experimental moisture ratio; $M R_{\text {pred, }}$ ${ }_{i}$ is the predicted moisture ratio, $N$ is the number of experimental data points and $n_{p}$ is the number of parameters in model.

\subsection{Optimization of superheated steam drying}

G. cambogia samples were prepared following the central composite design (CCD) which each numeric factor is varied over 5 levels that are $\pm \alpha$ (axial points), \pm 1 (factorial points) and center point. In this experimental design, $\alpha$ of 1.0 (face centered) option was chosen so that all the parameters were within the desired range. Number of design points generated were 8 'not center point' and 5 'center points', giving a total of 13 assays from two independent numeric factors, time and temperature. The design points of time and temperature were varied, in the range of 45 to $50 \mathrm{mins}$ and between 150 to $250^{\circ} \mathrm{C}$. Table 1 shows the generated design points for G. cambogia fruit rinds using Minitab software (Version 16.1.1, Minitab Inc., USA). The dependent variables or responses are moisture content, colour parameter, $L^{*}$ (lightness) and acid number. The experiment was randomized, repeated twice for the entire set of 13 assays and mean values from the experiments were taken for optimization analysis.

Table 1. The experimental design for optimization of $G$. cambogia fruit rinds

\begin{tabular}{ccccc}
\hline \multirow{2}{*}{ Run Order } & \multicolumn{2}{c}{ Codified } & \multicolumn{2}{c}{ Decodified } \\
\cline { 2 - 5 } & Time & Temperature & Time $(\mathrm{min})$ & Temperature $\left({ }^{\circ} \mathrm{C}\right)$ \\
\hline 1 & 1 & 0 & 55 & 200 \\
2 & 0 & 0 & 50 & 200 \\
3 & -1 & 1 & 45 & 250 \\
4 & 0 & 0 & 50 & 200 \\
5 & 0 & 1 & 50 & 250 \\
6 & -1 & 0 & 45 & 200 \\
7 & 1 & 1 & 55 & 250 \\
8 & 0 & 0 & 50 & 200 \\
9 & 1 & -1 & 55 & 150 \\
10 & 0 & 0 & 50 & 200 \\
11 & 0 & -1 & 50 & 150 \\
12 & -1 & -1 & 45 & 150 \\
13 & 0 & 0 & 50 & 200 \\
\hline
\end{tabular}

\subsection{Moisture content determination}

Moisture content analysis (Chemists and Horwitz, 1990) was done on the samples collected in duplicate. Moisture can with lid was cleaned and dried in hot air oven (Memmert, UM600, Schwabach, Germany) for at least $2 \mathrm{hrs}$ at $105^{\circ} \mathrm{C}$. The dried moisture can and the lid were removed from hot air oven and left to cool in a desiccator. The weight of the moisture can with lid was measured by digital balance and the reading was recorded. Approximately 2 to $3 \mathrm{~g}$ of the blended sample was weighed into the moisture can and dried in hot air oven at $105^{\circ} \mathrm{C}$ for $16 \mathrm{hrs}$. The moisture can was kept semi-covered by the lid to allow moisture to leave the sample. After dried for overnight, moisture can was removed from hot air oven, realigned lid to close and cooled in desiccators until the weight of moisture can and the sample was determined. The calculation was performed to obtain the percentage of moisture content on the wet basis of the samples. 


\subsection{Titratable acidity}

Preparation of chemical required for titratable acidity test was done prior to the test. Toluene-isopropyl alcohol mixture was prepared by mixing toluene and 2-propanol in 1:1 ratio. $0.1 \mathrm{~N}$ alcoholic $\mathrm{KOH}$ was prepared according to procedures listed by Pharmaceutical Guidelines (2015). $6 \mathrm{~g}$ of $\mathrm{KOH}$ was weighed and dissolved in $5 \mathrm{~mL}$ of distilled water. The solution was then transferred to a $1000 \mathrm{~mL}$ volumetric flask and top up with $95 \%$ ethanol until the benchmark to produce $1000 \mathrm{~mL}$ solution. The solution was stoppered and allowed to stand for $24 \mathrm{hrs}$. The clear solution on the top was transferred in a tightly closed container and standardization of the solution was carried out. Approximately 1 to $2 \mathrm{~g}$ of blended sample was weighed into $100 \mathrm{~mL}$ beaker. 50 to $100 \mathrm{~mL}$ toluene-isopropyl alcohol mixture was added to the sample and left to stand for 10 mins. The mixture was then filtered using Whatman ${ }^{\circledR}$ Grade 1 qualitative filter paper into a conical flask and added with $0.1 \mathrm{ml}$ of phenolphthalein solution. Titration with $0.1 \mathrm{~N}$ alcoholic $\mathrm{KOH}$ was performed until a permanent faint pink which persists for at least 10 seconds appeared.

Acid value of the sample was calculated as follow:

$$
\text { Acid value }=\frac{\mathrm{mL} \text { of alc. } \mathrm{KOH} \text { soln. } \times 0.1 \mathrm{~N} \times 56.1}{\text { Weight of sample }(\mathrm{g})}
$$

Note that difference between duplicate should not exceed $0.1 \mathrm{mg} \mathrm{KOH} / \mathrm{g}$ sample.

\subsection{Colour measurement}

$L^{*}$ (lightness) of blended samples were measured by using spectrophotometer (KONICA MINOLTA, CM3500d, Osaka, Japan). The measurement was performed via SpectraMagic ${ }^{\mathrm{TM}} \mathrm{NX}$ computer software and calibration was carried out according to the user manual for powder before sample measurement. First, target mask for petri dish (CM-A127) was placed on the instrument's shutter. The instrument setting was changed to reflectance: $d / 8$ (diffuse illumination), specular component excluded (SCE), large aperture and target sample holder petri dish. Then, aperture of target mask was covered by zero calibration box (CM-A124) to perform zero calibration followed by white calibration with white calibration plate (CM-A120).After completed the calibration steps, measurement of samples can proceed. The sample was filled into a petri dish and placed on the target mask then covered with zero calibration mask. The measurement on target sample was taken for 3 replications and data were presented in an average.

\subsection{Statistical analysis}

All data generated were analyzed with Minitab software (Version 16.1.1, Minitab Inc., USA). Analysis of variance and RSM were conducted. All the responses ( $\mathrm{L}^{*}$ value of colour, moisture content, and acid value) were analyzed to diagnose the significant effects of each factor over each response. The data of responses in relation to factors was each fitted into a second-order polynomial equation in a function of $X$.

$$
Y=\beta_{0}+\beta_{1} X_{1}+\beta_{2} X_{2}+\beta_{12} X_{1} X_{2}+\beta_{11} X_{1}{ }^{2}+\beta_{22} X_{2}{ }^{2}
$$

Where; $\mathrm{Y}$ is the predicted response; $\beta_{0}$ is a constant coefficient; $\beta_{1}$ and $\beta_{2}$ are linear regression coefficients; $\beta_{12}$ is the interaction regression coefficient; $\beta_{11}$ and $\beta_{22}$ are quadratic regression coefficients; $X_{1}$ is the coded value $(+1,0,-1)$ of factor, time; and $X_{2}$ is the coded value $(+1,0,-1)$ of factor, temperature.

$R^{2}$ values of the regressions to above $90 \%$ were used to indicate the adequacy of the models and insignificant lack-of-fit test ( $>0.05)$ as good indicators of the fitness. Optimization analysis was carried out next using the same software. The desirability functions proposed by Derringer (1980) were used to determine the optimum point prediction for drying of G. cambogia. The desirability function method transforms each response into an individual desirability value by defining the goals and boundaries and later combined all individual desirability into a single measure using a geometric mean (Wan and Birch, 2011). The highest desirability value is 1. The optimum quality of $G$. cambogia was determined following target values of moisture content of $15.50 \%$, with maximum of $\mathrm{L}^{*}$ and acid number. The moisture content of $15.50 \%$ refers to the commercially available dried G. cambogia products purchased from a local market in Penang, Malaysia.

\section{Results and discussions}

\subsection{Kinetic study}

\subsubsection{Kinetic drying curves of Garcinia cambogia using SSD}

G. cambogia fruit rinds with initial moisture content approximately $87 \%$ on wet basis were dried in a superheated steam oven until its equilibrium moisture content was reached. The kinetic drying curves of $G$. cambogia fruit rinds at temperatures of 150, 200 and $250^{\circ} \mathrm{C}$ are shown in Figure 1a. The moisture content of G. cambogia fruit rinds decreased with time when heat from the superheated steam withdrew the moisture away from the thin layer. The kinetic drying curve of superheated steam drying at $250^{\circ} \mathrm{C}$ decreased in the steepest manner followed by $200^{\circ} \mathrm{C}$ and lastly the least steep at $150^{\circ} \mathrm{C}$ (Figure 1a). The different sloppiness of 
the curves between different temperatures was due to the different drying rates. The kinetic drying of G. cambogia fruits demonstrated two distinct drying rates which are constant drying rate and falling rate. In the first 15 mins period, constant drying period occurred which moisture is freely available on the surface and immediate moisture removal was allowed through evaporation. After the surface moisture had been exhausted, the process went into falling rate of drying period which internal diffusion of moisture to the surface was required to remove the moisture. The amount of moisture available became progressively scarce and the drying rate decreased with time until constant equilibrium moisture content was achieved.

Generally, drying at higher temperature increases the drying rate and equilibrium moisture content can be achieved in a shorter time than lower temperature. As shown in Figure 1a, equilibrium moisture content was achieved at 55 mins of drying when drying was performed at $250^{\circ} \mathrm{C}$ whereas required more than 90 mins

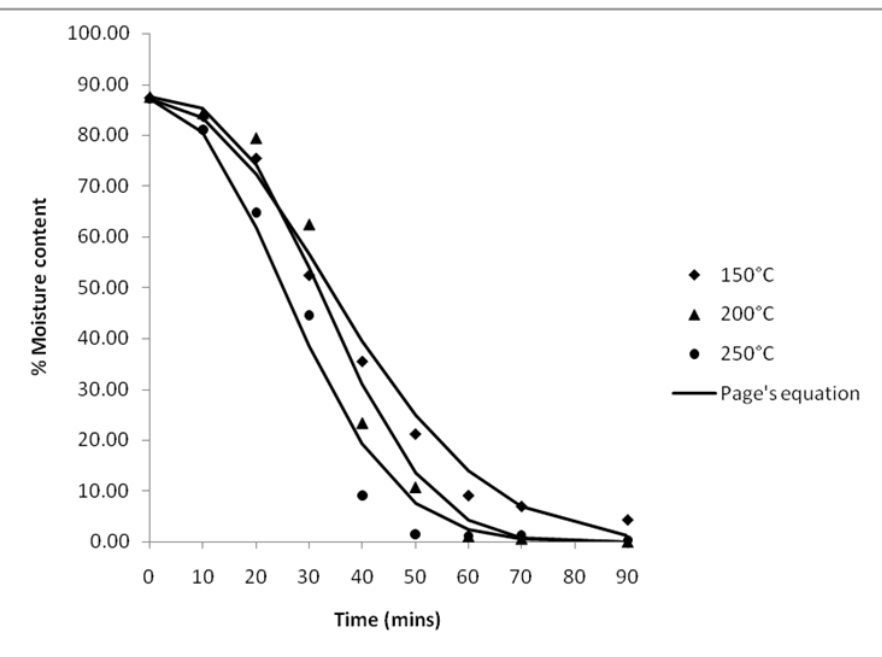

Figure 1a. Drying curves of G. cambogia fruit rinds by using superheated steam drying at temperature 150, 200 and $250^{\circ} \mathrm{C}$ fitted according to Page's equation.

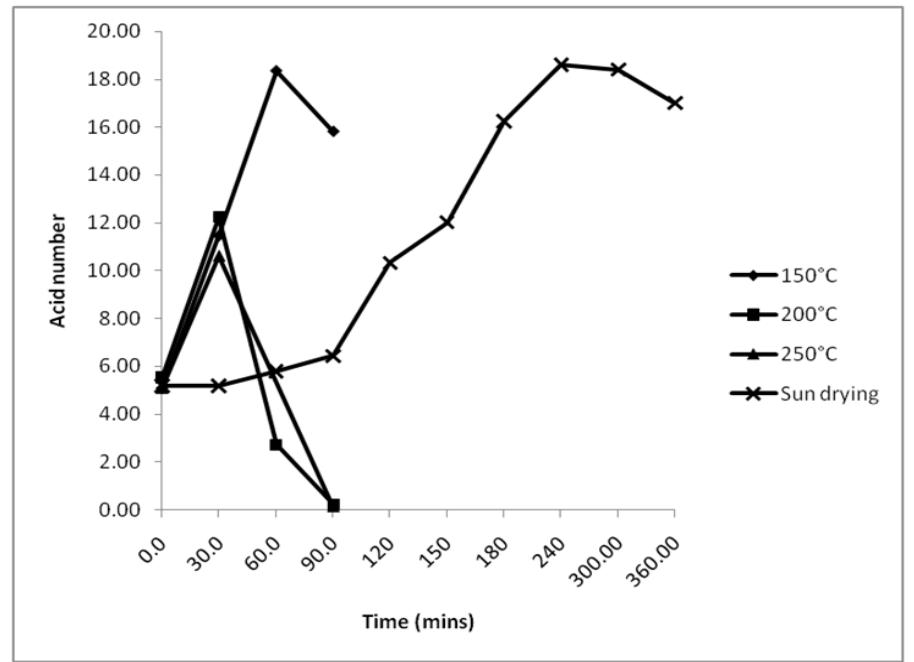

Figure 1c. The relationship of acid number with drying time at 150,200 and $250^{\circ} \mathrm{C}$ of superheated steam drying and sun drying. for drying at $150^{\circ} \mathrm{C}$. The higher drying temperature implies larger driving force for heat transfer and leads to higher values of moisture diffusivity (Methakhup et al., 2005). The idea of the relationship between temperature and moisture diffusivity can be better known through the temperature dependent effective diffusivity $\left(D_{\text {eff }}\right)$ equation which followed an Arrhenius relationship (Suarez et al., 1980).

\subsubsection{Comparison of Garcinia cambogia by drying kinetic of SSD and SD}

From the results obtained, the objective of the study was achieved as superheated steam drying was more efficient in term of time saving. The drying time of $G$. cambogia fruit rinds was reduced to an hour time as compared to sun drying under an open environment which was truly affected by the weather, humidity and air velocity which took 6 hrs and only happened to reduce the moisture content to $17.47 \%$ on a wet basis (Figure 1b). However, drying of G. cambogia fruit rinds

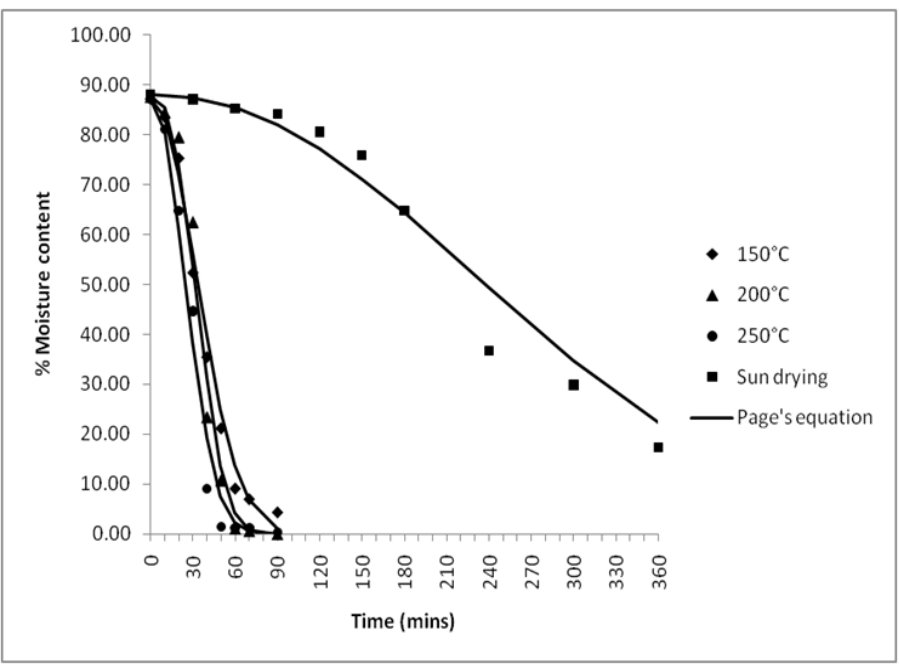

Figure 1b. Comparison of drying kinetic of G. cambogia fruit rinds by superheated steam drying and sun drying with data fitted according to Page's equation.

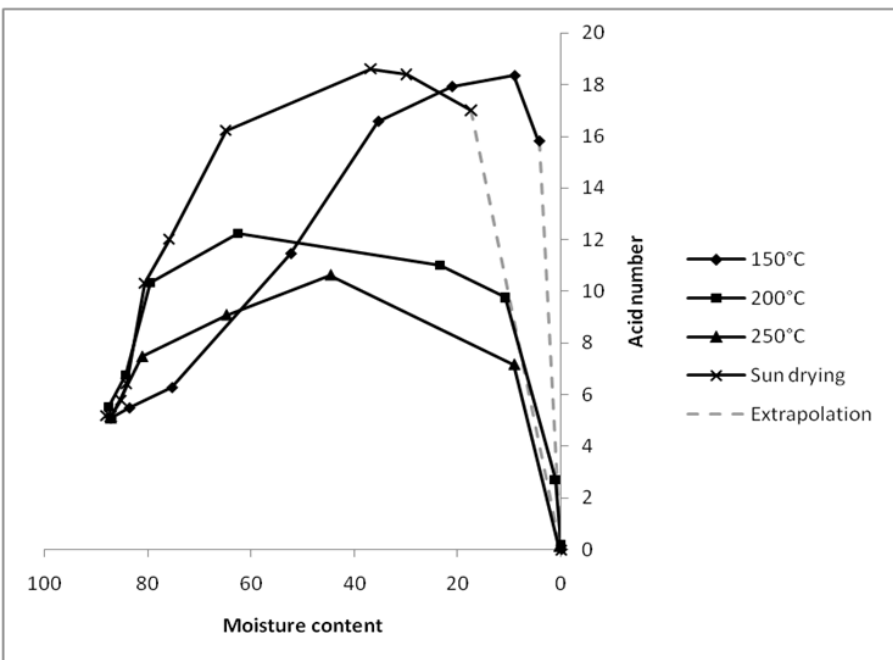

Figure 1d. The relationship of acid number with moisture content during drying process 
at high temperature is not favourable even though shorter drying time can be achieved. High heat treatment on the fruit would eventually cause thermal damages to organic substances presence in the fruit and affect the overall final product quality. G. cambogia is rich in (-) hydroxycitric acid (HCA) which has antiobesity potency (Gogoi et al., 2014). The organic acids also contribute to the characteristic sourness (Raju and Reni, 2001) and thus often $G$. cambogia dried fruit rinds are used as flavouring and condiments in Indian and Thai cuisine (Great Recipe Tips, 2014). Hence, the consideration of temperature used in superheated steam drying is significant in order to achieve a balance in drying time and quality.

\subsubsection{The relationship of acidity and drying time of $S S D$ and $S D$}

The relationship of acid number and drying time at different drying temperatures were illustrated in Figure 1c. The acid number was found to have a common trend which the value increase with drying time until a turning point, decreased when further dried. This trend was clearly seen in G. cambogia fruit rinds dried by the superheated steam oven at 150,200 and $250^{\circ} \mathrm{C}$. Superheated steam drying at $200^{\circ} \mathrm{C}$ and $250^{\circ} \mathrm{C}$ showed acid numbers both peaked at 30 mins of drying while for drying at $150^{\circ} \mathrm{C}$ the acid number peaked at 60 mins of drying. For sun drying, a continuous increased of the acid number was observed till the fourth hour of the drying period.

\subsubsection{The relationship of acid number with moisture during drying process}

Relationship of acid number and moisture content at different drying temperatures were illustrated in Figure 1d. The experimental data suggested that the rose in acid number can be attributed to initial heat provided during the drying process, however, was limited by moisture content and further heating. An illusion line was used to give a better clarity on the effect of reduced in moisture content to the acid number.

The early stage of drying yields a higher acid number which does not correspond with the general perception that phytochemical compounds will be destroyed or damaged by high heat. This outcome opposed the research by Pacheco-Palencia et al. (2009) and Song and Milner (2001) which discuss on thermal stability of phytochemicals in Acai fruit and garlic respectively. However, research reported by Chan et al. (2008) and Zhu (1998) supported the experimental outcome as research showed that heat treatments on herbs lead to the elimination, separation or release of phytochemical element which in turn changes the biological nature or creation of new biological characteristic in herbs extract. Lactonisation of hydroxycitric acid which usually happened during evaporation and concentration (Jayaprakasha and Sakariah, 2002) is likely to contribute to the high acid number in the early stage of drying. Further heating of fruit rinds affects the thermal stability of organic acids and also with a reduction in moisture content lead to destroy and breakdown thus having the acid number in decreasing trend with drying time.

\subsubsection{Modeling the drying behavior of Garcinia cambogia}

In this study, equilibrium moisture content $\left(M_{e}\right)$ for sun drying method was unable to determine as drying only took place in a duration of 6 hours and the moisture content has not yet to reach equilibrium moisture content. To achieve moisture level of 15 to $20 \%$, sun drying of $G$. cambogia under open environment required three to seven days under thin layer conditions (Raju and Reni, 2001). In order to provide a similar final state of drying, equilibrium moisture contents for all drying conditions were assumed to be $0 \%$ in wet basis. Several papers also adapted this assumption on equilibrium moisture content since the value was significantly less than initial moisture content and some with the reasons of fluctuating relative humidity during the drying process (McMinn, 2006). After obtaining data of moisture ratio at each drying time, drying rate constant $(k)$ and dimensionless constants ( $a$ and $N$ ) were determined from the intercept and slope of normalized equation of each model respectively. Page model, Lewis model and Henderson-Pabis model mathematical and normalized expression were shown as in Table 2. Empirical constant of Page model, Lewis model and Henderson-Pabis model equations were tabulated in Table 3 with coefficient of determination $\left(\mathrm{R}^{2}\right)$ indicating the fitness of each model to the drying kinetic of $G$. cambogia fruit rinds. RMSE (root mean squared error) and $\mathrm{X}^{2}$ (chi-square) were used to check the ability of the model to represent the drying data. Calculation of RMSE and $\mathrm{X}^{2}$ in Table 4 were based on equation (7) and equation (8) respectively.

Higher values of $\mathrm{R}^{2}$ suggested that the particular

Table 2. Thin layer models fitted to experiment data

\begin{tabular}{lll}
\hline \multicolumn{1}{c}{ Model } & Mathematical expression & \multicolumn{1}{c}{ Normalized expression } \\
\hline Page & $M R=\exp \left(-k t^{n}\right)$ & $\ln [-\ln (M R)]=\ln (k)+n \ln (t)$ \\
Lewis & $M R=\exp (-k t)$ & $\ln (M R)=-k t+1$ \\
Henderson-Pabis & $M R=a \exp (-k t)$ & $\ln (M R)=-k t+a$ \\
\hline
\end{tabular}


Table 3. Empirical constant of Page, Lewis and Henderson-Pabis equation

\begin{tabular}{ccccccccc}
\hline \multirow{2}{*}{ Temperature } & \multicolumn{3}{c}{ Page equation } & \multicolumn{2}{c}{ Lewis equation } & \multicolumn{3}{c}{ Henderson-Pabis equation } \\
\cline { 2 - 9 } & $k\left(\mathrm{~min}^{-1}\right)$ & $n$ & $\mathrm{R}^{2}$ & $k\left(\mathrm{~min}^{-1}\right)$ & $\mathrm{R}^{2}$ & $k\left(\mathrm{~min}^{-1}\right)$ & $a$ & 0.377 \\
\hline $150^{\circ} \mathrm{C}$ & $3.612 \times 10^{-4}$ & 2.084 & 0.982 & 0.048 & 0.849 & 0.038 & 0.951 & 0.907 \\
$200^{\circ} \mathrm{C}$ & $5.929 \times 10^{-5}$ & 2.647 & 0.969 & 0.08 & 0.905 & 0.083 & 1.198 & 0.907 \\
$250^{\circ} \mathrm{C}$ & $5.861 \times 10^{-4}$ & 2.129 & 0.956 & 0.077 & 0.897 & 0.069 & 0.518 & 0.915 \\
Sun drying & $4.980 \times 10^{-6}$ & 2.128 & 0.962 & 0.007 & 0.253 & 0.004 & 0.274 & 0.885 \\
\hline
\end{tabular}

Table 4. Model prediction evaluation

\begin{tabular}{ccccccc}
\hline \multirow{2}{*}{ Temperature } & \multicolumn{2}{c}{ Page equation } & \multicolumn{2}{c}{ Lewis equation } & \multicolumn{2}{c}{ Henderson-Pabis equation } \\
\cline { 2 - 6 } & RMSE & $\mathrm{X}^{2}$ & RMSE & $\mathrm{X}^{2}$ & RMSE & $\mathrm{X}^{2}$ \\
\hline $150^{\circ} \mathrm{C}$ & 0.0364 & $1.863 \times 10^{-8}$ & 0.6247 & $3.691 \times 10^{-1}$ & 0.1634 & $2.294 \times 10^{-2}$ \\
$200^{\circ} \mathrm{C}$ & 0.0505 & $5.022 \times 10^{-10}$ & 0.6143 & $3.691 \times 10^{-1}$ & 0.8084 & $7.747 \times 10^{-1}$ \\
$250^{\circ} \mathrm{C}$ & 0.0527 & $4.095 \times 10^{-8}$ & 0.5913 & $3.691 \times 10^{-1}$ & 0.2714 & $6.580 \times 10^{-1}$ \\
Sun drying & 0.0561 & $3.101 \times 10^{-12}$ & 0.7363 & $3.691 \times 10^{-1}$ & 0.1412 & $1.242 \times 10^{-2}$ \\
\hline
\end{tabular}

model has a better prediction on the drying behaviour of G. cambogia fruit rinds (Giri and Prasad, 2007; Onwude et al., 2016). The reduced values for RMSE and $\mathrm{X}^{2}$ also represents the ability of the model to represents the drying data. Reduced $\mathrm{X}^{2}$ takes in the number of constants in the model and with the magnitude of this parameter the model is described to have higher reliability in presenting the drying data (McMinn, 2006). By various means of statistical parameters, the best fit was decided for highest $\mathrm{R}^{2}$ and minimum RMSE and $\mathrm{X}^{2}$ (Kadam et al., 2011). From Table 3 and Table 4, Page model equation was showed as best model fitted to the experimental drying data of superheated steam drying at 150,200 and $250^{\circ} \mathrm{C}$ and sun drying. The $\mathrm{R}^{2}$ values obtained were relatively higher range from 0.956 to 0.982 compared to Lewis model equation and Henderson -Pabis model equation with significant reduced in RMSE and $\mathrm{X}^{2}$ values.

Overall, drying rate constants $(k)$ of $G$. cambogia fruit rinds by using superheated steam was higher as compared to sun drying. Drying rate constant $(k)$ increased as temperature increased and SSD method had overall higher drying rates ranged from $5.929 \times 10^{-5}$ to $5.861 \times 10^{-4} \mathrm{~min}^{-1}$ than sun drying method which was $4.980 \times 10^{-6} \mathrm{~min}^{-1}$. The higher drying rate indicated that time required for reducing moisture content of $G$. cambogia to a desire level has been shortened. This implies that drying of fruit rinds by using superheated steam oven is much faster than sun drying. Drying rate also showed linear relationship with superheated steam drying temperature which at $150^{\circ} \mathrm{C}$ was $3.612 \times 10^{-4} \mathrm{~min}^{-}$ ${ }^{1}$ and increased to $5.861 \times 10^{-4} \mathrm{~min}^{-1}$ at $250^{\circ} \mathrm{C}$ in Page model. Similar trend was observed in Lewis model equation and Henderson-Pabis model equation too which the drying rates increased with temperature increased. The increased in drying rates with increased of drying temperature were due to effective diffusivity which is temperature dependent (Vaccarezza et al., 1974). The increased in drying temperature causes the driving force for heat and mass transfer to increase and hence increase the drying rate (Methakhup et al., 2005).

\subsection{Response surface methodology and optimization}

Optimization of drying of $G$. cambogia fruit rinds was done by response surface methodology. Regression coefficients of the second-order polynomial model presented in Table 5 yield the following equations:

$Y_{1}, Y_{2}$ and $Y_{3}$ represents moisture content, acid number and lightness, respectively.

The independent and dependent variables were fitted to the equations and examination of the goodness of fit was carried out by determining $\mathrm{R}^{2}$ values and analysis of variance on the effect of time and temperature of drying towards the responses as shown in Table 6 . The results denoted that the models for moisture content, acid

Table 5. Regression coefficients and the associated probability (P-value) of the second-order polynomial response models

\begin{tabular}{ccccccc}
\hline \multirow{2}{*}{ Term } & \multicolumn{2}{c}{ Moisture content, $\mathrm{Y}_{1}$} & \multicolumn{2}{c}{ Acid number, $\mathrm{Y}_{2}$} & \multicolumn{2}{c}{ Lightness, $\mathrm{Y}_{3}$} \\
\cline { 2 - 7 } & $\beta$ & P-value & $\beta$ & P-value & $\beta$ & P-value \\
\hline Constant & 0.5462 & 0.38 & 0.7352 & 0.067 & 18.9555 & $0.000^{*}$ \\
$\mathrm{X}_{1}$ & -2.9133 & $0.001 *$ & -1.7517 & $0.001 *$ & -0.2533 & 0.38 \\
$\mathrm{X}_{2}$ & -5.385 & $0.000^{*}$ & -5.015 & $0.000^{*}$ & -2.0367 & $0.000^{*}$ \\
$\mathrm{X}_{1} \mathrm{X}_{2}$ & 2.1925 & $0.017^{*}$ & 1.6975 & $0.004 *$ & -0.0475 & 0.89 \\
$\mathrm{X}_{1}{ }^{2}$ & 2.5083 & $0.021^{*}$ & 0.1619 & 0.752 & 0.8507 & $0.070^{*}$ \\
$\mathrm{X}_{2}{ }^{2}$ & 5.0233 & $0.001^{*}$ & 4.6019 & $0.000^{*}$ & 0.6707 & 0.137 \\
\hline
\end{tabular}

$\beta$ is the regression coefficient. $\mathrm{X}_{1}$ and $\mathrm{X}_{2}$ are coded factor for time and temperature respectively. ${ }^{*} p<0.05$ denotes that there is significant effects 
number and lightness are at satisfactory level as the $\mathrm{R}^{2}$ are particularly high for all models $\left(\mathrm{R}^{2}>0.900\right)$. Results showed that there was no significant lack of fit $(p>0.05)$ in response of acid number and lightness. However, moisture content was significant lack of fit suggested that the model was not applicable to represent the data. Repetition on drying procedures were performed in order to improve the lack of fit, but was unsuccessful. Pua et al. (2007) reported that lack of fit may be due to the large experimental region covered in a study. This report is invalid to explain current lack of fit as only two independent variables involved in this model. While Box and Draper (1987) explained significant lack of fit of a model might due to the lack of variable in the experimental study which appropriate functions of independent variables were not included. After all, the model with a significant lack of fit could still be used if most of the models showed no significant lack of fit. Further verification of the results will be needed to ensure the usage is unlikely to be questionable and values obtained through calculations using model equation shall possessed good agreement with the experimental value (Torreggiani et al., 1995).

Table 6. Analysis of variance on the independent variables as linear, quadratic and interaction terms on the response variables

\begin{tabular}{lcccc}
\hline \multirow{2}{*}{ Source } & df & \multicolumn{3}{c}{ Sequential sum of squares } \\
\cline { 3 - 5 } & & Moisture content & Acid number & Lightness \\
\hline Regression & 5 & $377.007^{*}$ & $251.175^{*}$ & $30.4779^{*}$ \\
Linear & 2 & $224.914^{*}$ & $169.311^{*}$ & $25.2731^{*}$ \\
Square & 2 & $132.864^{*}$ & $70.338^{*}$ & $5.1957^{*}$ \\
Interaction & 1 & $19.228^{*}$ & $11.526^{*}$ & 0.009 \\
Residual error & 7 & 13.78 & 14.692 & 3.0757 \\
Lack of fit & 3 & $12.657^{*}$ & 3.438 & 1.4603 \\
Pure error & 4 & 1.123 & 1.254 & 1.6155 \\
Total & 12 & 390.787 & 255.867 & 33.5536 \\
$\mathrm{R}^{2}(\%)$ & & 96.47 & 98.17 & 90.38 \\
\hline
\end{tabular}

$* p<0.05$ denotes that there is significant effect.

From Table 6, time and temperature were showed to be significant factors $(p<0.05)$ for moisture content, acid number, and lightness. Time and temperature appeared to have significant effects on moisture content and acid number in linear, quadratic and interaction terms whereas only linear and quadratic terms showed the significant effect to lightness. From Table 5, it was observed that significant first and second order polynomial models were found for moisture content which had a negative linear effect and positive non-linear effect with drying time and temperature. Figure $2 \mathrm{a}$ was the surface plot of moisture content to temperature and time. The surface plot indicated that moisture content decreased with the increased of temperature and time. The increased in temperature created a larger driving force for heat and mass transfer and thus promote efficient diffusivity which allowed moisture to leave the drying surface. During drying, moisture content was evaporated and continuously diffused to the surface. As drying time was prolonged, more and more moisture content can be drawn out from G. cambogia fruit rinds.

Surface Plot of Moisture Content vs Temperature, Time

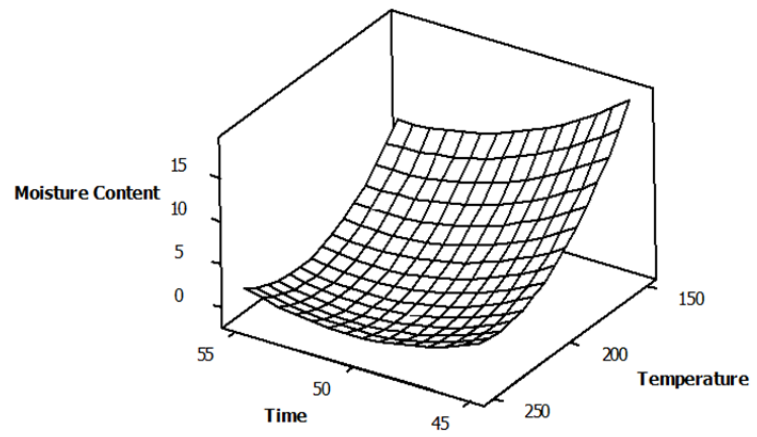

Figure 2a. Interaction effects of time and temperature on moisture content.

In acid number response, temperature factor contributed to negative linear effect and positive nonlinear effect whereas time factor showed significant negative linear effect. Figure $2 \mathrm{~b}$ shows the interaction effects of time and temperature on the acid number. The results indicated that acid number significantly dropped as temperature increased but affected moderately by time. In the first order polynomial, it was found that temperature had a negative effect on lightness. Whilst a positive effect on secondary order polynomial of time was found on lightness. In Figure $2 \mathrm{c}$, lightness was affected by temperature factor and decreasing trend with increased of temperature was observed. Time factor caused smaller changes to lightness which the lightness decreased slightly with increased of drying time. According to Krokida et al. (1998), thermal processing affects the food quality either by discoloration or browning which are caused by various reactions, including Maillard reactions, phenol polymerization, and pigment destruction. The lightness of G. cambogia fruit rinds decreased with increased of drying time and temperature were mainly attributed to Maillard reaction. The browning reaction of dried fruit rinds was supported by Raju and Reni (2001) which reported G. cambogia fruit rinds is rich in non-volatile acid and contains $15 \%$ reducing sugar and the complete removal of moisture to a level of 15 to $20 \%$ yield a coal black colour dried rinds.

Determination the optimum condition of superheated steam drying to obtain a preferable dried G. cambogia fruit rind quality with moisture content target at $15.5 \%$, maximum acid number and lightness shown in Figure 3. The composite desirability of the desired optimum 


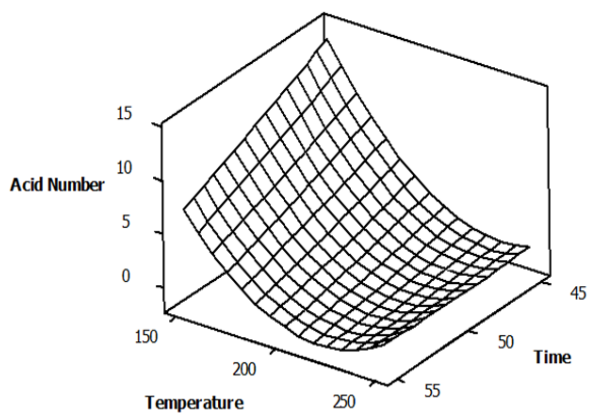

Figure $2 \mathrm{~b}$. Interaction effects of time and temperature on acid number.

factors for dried fruit rinds was 0.93375 with a drying time of 46.6508 mins and drying temperature $150^{\circ} \mathrm{C}$. In order to make the drying parameters feasible in experimental runs, the drying time is adjusted to 46.6 minutes and drying at $150^{\circ} \mathrm{C}$. From the adjustment the composite desirability and individual desirability of moisture content are decreased slightly, however with the individual desirability of acid number and lightness increased slightly. Therefore, the optimum drying time and temperatures of G. cambogia is 46.6 mins and $150^{\circ} \mathrm{C}$ respectively with desirability value 0.91378 .

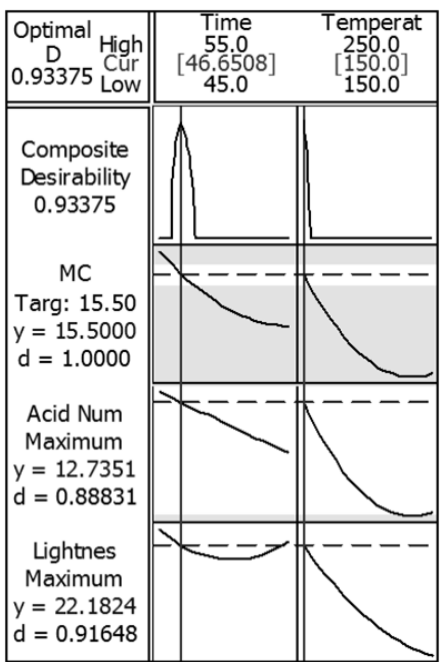

(A)

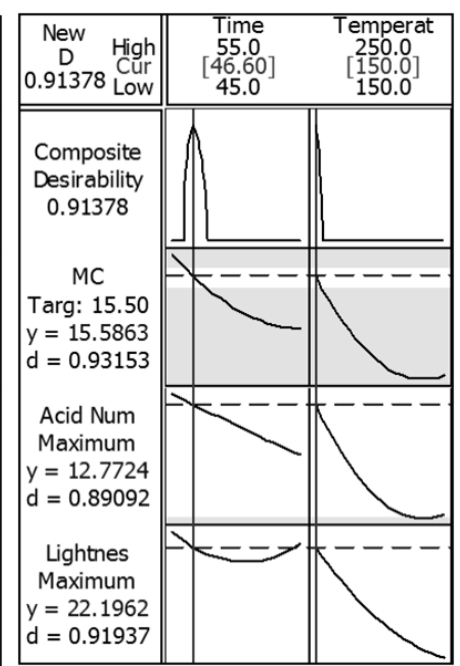

(B)
Figure 3. Optimization plot of superheated steam drying of G. cambogia with composite desirability and individual desirability of each response.

\section{Conclusion}

This research studies the kinetic drying of $G$. cambogia by sun drying and superheated steam drying method. In general, kinetic drying of $G$. cambogia by superheated steam drying demonstrated constant drying rate and falling rate. Equilibrium moisture content of $G$. cambogia was achieved within 100 mins by superheated steam drying whilst sun drying required more than $6 \mathrm{hrs}$. Superheated steam drying provides a significant shorter

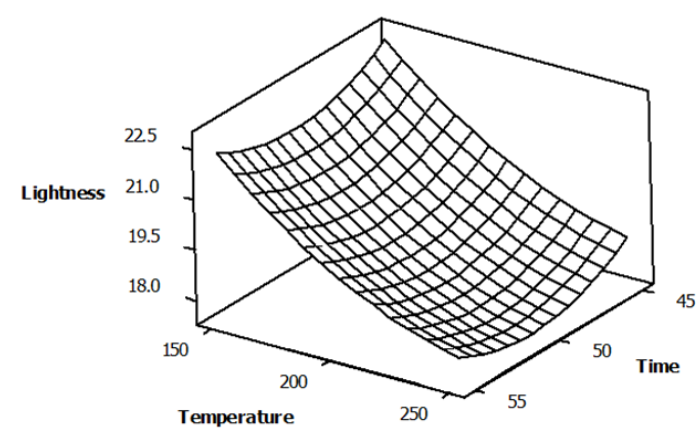

Figure 2c. Interaction effects of time and temperature on lightness.

drying time due to the higher drying rates. The acid number of $G$. cambogia was shown affected by temperature and moisture content. The acid number increased in the early stage of superheated drying and decreased when moisture content was significantly reduced. Page model was found to be the best in describing the drying behaviour of G. cambogia as compared to Lewis and Henderson-Pabis models. Optimization of superheated steam drying of Garcinia cambogia was done by response surface methodology employing central composite design. Time and temperature were the independent variables and found to have significant effects on the dependent variables: moisture content, acid number and lightness. The optimum conditions of drying time and drying temperature of $G$. cambogia were identifies as 46.6 mins and $150^{\circ} \mathrm{C}$ respectively with desirability value 0.91378 . These findings indicate that the kinetic drying of $G$. cambogia by superheated steam could be done to fit into the larger scale of industrial drying.

\section{Acknowledgements}

Authors would like to acknowledge Short Term Grant Universiti Sains Malaysia (304/ PTEKIND/6313331) for funding this project.

\section{References}

Box, G.E.P. and Draper, N.R. (1987). Wiley series in probability and mathematical statistics. Empirical model-building and response surfaces. Oxford, England: John Wiley and Sons.

Caixeta, A.T., Moreira, R. and Castell-Perez, M.E. (2002) Impingement drying of potato chips. Journal of Food Process Engineering, 25(1), 63-90. https:// doi.org/10.1111/j.1745-4530.2002.tb00556.x

Chan, L.W., Cheah, E.L.C., Saw, C.L.L., Weng, W. and Heng, P.W.S. (2008) Antimicrobial and antioxidant activities of Cortex magnoliae officinalis and some other medicinal plants commonly used in South-East 
Asia. Chinese Medicine, 3, 1-10. https:// doi.org/10.1186/1749-8546-3-15

Chemists, A.A. and Horwitz, W. (1990) Official methods of analysis. Vol. 1. 15th ed. Arlington: AOAC.

Derringer, G. and Suich, R. (1980) Simultaneous optimization of several response variables. Jouirnal of Quality Technology, 12(4), 214-219 https:// doi.org/10.1080/00224065.1980.11980968

Giri, S.K. and Prasad, S. (2007) Drying kinetics and rehydration characteristics of microwave-vacuum and convective hot-air dried mushrooms. Journal of Food Engineering, 78(2), 512-521. https://doi.org/10.1016/ j.jfoodeng.2005.10.021

Gogoi, A., Gogoi, N. and Neog, B. (2014) Estimation of (-)-hydroxycitric acid (HCA) in Garcinia lanceaefolia Roxb. using novel HPLC methodology. International Journal of Pharmaceutical Science, 5 (11), 4993-4997.

Guillard, V., Bourlieu, C. and Gontard, N. (Eds.). (2013). Relationship Between Multiscale Food Structure and Moisture Transfer Properties. In Food Structure and Moisture Transfer. Vol. 8, p. 35-44. USA: Springer. https://doi.org/10.1007/978-1-4614-6342-9_3

Haber, S.L., Awwad, O., Phillips, A., Park, A.E. and Pham, T.M. (2018) Garcinia cambogia for weight loss. American Journal of Health-System Pharmacy, 75(2), 17-22. https://doi.org/10.2146/ajhp160915

Hamawand, I., Yusaf, T. and Bennett, J. (2014) Study and modelling drying of banana slices under superheated steam. Asia-Pacific Journal of Chemical Engineering, 9(4), 591-603. https://doi.org/10.1002/ apj.1788

Henderson, S.M. (1974) Progress in developing the thin layer drying equation. Transactions of the ASAE, 17 (6), 1167-1168. https://doi.org/10.13031/2013.37052

Jayaprakasha, G.K. and Sakariah, K.K. (2002) Determination of organic acids in leaves and rinds of Garcinia indica (Desr.) by LC. Journal of Pharmaceutical and Biomedical Analysis, 28(2), 379 -384. https://doi.org/10.1016/S0731-7085(01)006239

Kadam, D.M., Goyal, R.K. and Gupta, M.K. (2011) Mathematical modeling of convective thin layer drying of basil leaves. Journal of Medicinal Plants Research, 5(19), 4721-4730

Krokida, M.K., Tsami, E. and Maroulis, Z.B. (1998) Kinetics on color changes during drying of some fruits and vegetables. Drying Technology, 16(3-5), 667-685. doi.org/10.1080/07373939808917429 https://

McMinn, W.A.M. (2006) Thin-layer modelling of the convective, microwave, microwave-convective and microwave-vacuum drying of lactose powder. Journal of Food Engineering, 72(2), 113-123. https://doi.org/10.1016/j.jfoodeng.2004.11.025

Methakhup, S., Chiewchan, N. and Devahastin, S. (2005) Effects of drying methods and conditions on drying kinetics and quality of Indian gooseberry flake. $L W T$ Food Sciene and Technology, 38(6), 579-587. https:// doi.org/10.1016/j.lwt.2004.08.012

Mujumdar, A.S. (2006) Handbook of Industrial Drying. $3^{\text {rd }}$ ed. Florida, USA: CRC Press. https:// doi.org/10.1201/9781420017618

Onwude, D.I., Hashim, N., Janius, R.B., Nawi, N.M. and Abdan, K. (2016) Modeling the thin-layer drying of fruits and vegetables: A review. Comprehensive Reviews in Food Science and Food Safety, 15(3), 599 -618. https://doi.org/10.1111/1541-4337.12196

Osman M.B. and Milan, A.R. (2006). Fruits for the future 9: Mangosteen (Garcinia mangostana L.). Southampton, UK: Southampton Centre for Underutilised Crops.

Pacheco-Palencia, L.A., Duncan, C.E. and Talcott, S.T. (2009) Phytochemical composition and thermal stability of two commercial açai species, Euterpe oleracea and Euterpe precatoria. Food Chemistry, 115(4), 1199-1205. https://doi.org/10.1016/ j.foodchem.2009.01.034

Prachayawarakorn, S., Soponronnarit, S., Wetchacama, S. and Jaisut, D. (2002) Desorption isotherms and drying characteristics of shrimp in superheated steam and hot air. Drying Technology, 20(3), 669-684. https://doi.org/10.1081/DRT-120002823

Pronyk, C., Cenkowski, S. and Muir, W.E. (2004) Drying foodstuffs with superheated steam. Drying Technology, 22(5), 899-916. https://doi.org/10.1081/ DRT-120038571

Pua, C.K., Hamid, N.S.A., Rusul, G. and Rahman, R.A. (2007) Production of drum-dried jackfruit (Artocarpus heterophyllus) powder with different concentration of soy lecithin and gum arabic. Journal of Food Engineering, 78(2), 630-636. https:// doi.org/10.1016/j.jfoodeng.2005.10.041

Raju, V.K. and Renim, M. (2001). Kokam and cambodge. In Peter, K.V. (Ed.). Handbook of herbs and spices. Vol. 1., p. 207-215. Cambridge, England: Woodhead Publishing Limited. https:// doi.org/10.1533/9781855736450.207

Rittirut, W. and Siripatana, C. (2006). Drying characteristics of Garcinia atroviridis. Walailak Journal of Science and Technology, 3, 13-32

Roberts, J.S., Kidd, D.R. and Padilla-Zakour, O. (2008) Drying kinetics of grape seeds. Journal of Food Engineering, 89(4), 460-465. https://doi.org/10.1016/ 
j.jfoodeng.2008.05.030

Song, K. and Milner, J.A. (2001) The influence of heating on the anticancer properties of garlic. The Journal of Nutrition, 131(3), 1054S-1057S. https:// doi.org/10.1093/jn/131.3.1054S

Suarez, C., Viollaz, P. and Chirife, J. (1980) Diffusional analysis of air drying of grain sorghum. International Journal of Food Science and Technology, 15(5), 523 -531. https://doi.org/10.1111/j.13652621.1980.tb00971.x

Torreggiani, D., Toledo, R.T. and Bertolo, G. (1995) Optimization of vapor induced puffing in apple dehydration. Journal of Food Science, 60(1), 181$185 . \quad$ https://doi.org/10.1111/j.13652621.1995.tb05633.x

Upadhyay, V., Tiwari, A., Sharma, N., Joshi, H., Singh, B., Kalakoti, B.S. and Patil, V.M. (2013). Rapid Determination and Standardization of Garcinia Fruit Extract of Hydroxycitric acid (HCA) in Garcinia cambogia by HPLC. International Journal of Pharmacy and Integrated Life Sciences, 1, 25-31.

Vaccarezza, L.M., Lombardi, J.L. and Chirife, J. (1974) Heat transfer effects on drying rate of food dehydration. The Canadian Journal of Chemical Engineering, 52(5), 576-579. https:// doi.org/10.1002/cjce.5450520506

Van Deventer, H.C. and Heijmans, R.M.H. (2001) Drying with superheated steam. Drying Technology, 19(8), 2033-2045. https://doi.org/10.1081/DRT100107287

Wan, W. and Birch, J.B. (2011). A semiparametric technique for the multi-response optimization problem. Quality and Reliability Engineering International, 27(1), 47-59. https://doi.org/10.1002/ qre. 1106

Zhu, Y.-P. (1998) Chinese materia medica: chemistry, pharmacology and applications. Florida, USA: CRC press 